Session 2630

\title{
Transferring the Knowledge in a Bridge Program: Engineering Students Become Coaches
}

\author{
Maria A. Reyes, Mary Ann McCartney, Mary R. Anderson-Rowland \\ Arizona State University
}

\begin{abstract}
A unique, very successful summer bridge program was held for incoming underrepresented minority freshman and transfer engineering students at Arizona State University (ASU) during the summer of 1996. The Minority Engineering Program (MEP) Summer Bridge Program was a two week residential program designed to ensure academic success for the 44 student participants. The program was supported by a grant from the Coalition to Increase Minority Degrees and ASU's College of Engineering and Applied Sciences (CEAS).
\end{abstract}

Unlike typical Bridge Programs taught by faculty and staff, the curriculum for this program was delivered by undergraduate engineering students. Three students, two women and one man, formed "Dream Team I" for the curriculum development and delivery for each day from 8:00 am to 5:00 p.m., when the dinner hour began. The evening hour activities from 6:00 p.m. until midnight were developed and supervised by "Dream Team II", composed of four additional undergraduate students, three males and one female, who were selected from the three underrepresented minority societies, AISES, NSBE and SHPE.

The program content was developed by both teams, with the support of the Director and the Program Coordinator of the CEAS Minority Engineering Program (MEP) and a faculty member. In particular, the curriculum was designed by Dream Team I in consultation with a CEAS Associate Professor. The coach professor met with the students on several occasions to plan the program, made himself available as a consulting coach during the first week of the program, and allowed the students full autonomy over the instruction during the second week.

The curriculum team determined that the students would be teamed to develop a Web Page to be presented at the conclusion of the program. After each module, the curriculum team reconvened to discuss progress and to make modifications for the following sessions. At their own initiative, each day, the two dream teams met during dinner in a transition meeting to evaluate student progress in the program and to better plan for the evening's activities.

The participants related very well to instructor "peers". The instructors had credibility since they had been through the same type of curriculum. Student evaluations of the program were extremely positive with particularly high points for the instruction portion of the Web Page development. Although the student instructors taught teaming, at the same time, they were forced to learn a lot about teaming and teaching. They had several conflicts to resolve among 
themselves. One is now considering teaching as a career. Curriculum team members continued to tutor students after the program creating a support structure for the students.

\section{Introduction}

A unique, very successful summer bridge program was held for incoming underrepresented minority freshman and transfer engineering students at Arizona State University (ASU) during the summer of 1996. The Minority Engineering Program (MEP) Summer Bridge Program was a two week residential program designed to ensure academic success for the 44 student participants. The program was supported by a grant from the Coalition to Increase Minority Degrees (CIMD) and ASU's College of Engineering and Applied Sciences (CEAS). (Note: CIMD is sponsored by the National Science Foundation, is affiliated with the Southern Rocky Mountain Alliance for Minority Participation, and is now called the Western Alliance to Expand Student Opportunities.)

The primary purpose of the program was to aid in the retention of students by assisting in their academic preparation prior to attending a class at ASU. Our statistics show that if our students are going to leave the CEAS, most will leave after the first or second semester ${ }^{1}$. The program was geared toward reducing student anxiety prior to classes and toward ensuring they felt at ease immediately upon starting their classes at ASU. Therefore, eligibility for the program required the participants be admitted into ASU's CEAS and registered in a department in the College of Engineering. Registration ensured that the student had medical clearance, academic advisement from a faculty member, and that they were serious about pursuing a degree in engineering. Secondary purposes of the program were to recruit students to ASU and to provide student financial support. The two week stay on campus exposed the students to ASU and gave them the opportunity to compete for scholarships.

The focus of the program was achieved by centering the curriculum around the introductory engineering course ECE 100: Introduction to Engineering Design. The catalog description of the course is the following:

Introduction to engineering design philosophy and methodology: computer modeling of systems, processes, and components; design for customer satisfaction, profitability, quality and manufacturing; economic analysis; flow charting; sketching CAD; and teaming. A term design project is included ${ }^{2}$.

This course is the first course that an engineering student will usually take in their curriculum and is a four semester hour, open-ended design course. The course has three components; laboratory, projects and modeling with six contact hours ${ }^{3}$.

\section{Initial Planning}

The critical elements of the MEP Summer Bridge Program were to introduce the incoming students to the campus, university life, and the engineering curriculum. When the planning for the program began, the MEP determined that there were five program goals that needed to be incorporated into the curriculum of the two week program. These goals were quickly outlined during the planning meetings as:

1. Build community among the participants and the current engineering students

2. Introduce the participants to computing at ASU 
3. Introduce the participants to engineering and more specifically incorporate:

- engineering documentation and design projects

- team building and team competition

- use of computer software such as Microsoft Word, Excel and PowerPoint

- problem solving skills

- research activities

4. Help the students achieve an attitude of "I can be a successful engineering student at ASU"

5. Address issues relevant to freshman students such as the function of the registrars office, financial aid, and academic advisement

The program began with the solicitation of a faculty member to develop and to deliver the curriculum element of the program. The first choice was Dr. Barry McNeill, Associate Professor of Engineering, who is one of the faculty members who developed and delivers the curriculum of ECE 100. Since most of the goals of the program were centered around this course, Dr. McNeill was the natural choice as the faculty member for this program. However, his advice at that time was that the absolute best people to deliver the curriculum were the undergraduate students who had previously taken the course. He felt this way for several reasons: (1) the participants would identify with and respect students near their own age who had already taken the class; (2) the participants could easily envision themselves as engineering students through the role modeling of the student teachers and, (3) the student teachers would strengthen their own skills and enjoy teaching the participants. He immediately thought of students who had taken his course and who had enjoyed it and done well. In the end the team consisted of one student whose expertise was in computer programming and computer utilities, another who enjoyed the team building skills and one whose skills were in the computer packages. Between these three students almost all of the desired elements of the program were covered.

The three students, two women and one man, formed "Dream Team I" for the curriculum development and delivery for each day from 8:00 am to 5:00 p.m., when the dinner hour began. The evening hour activities from 6:00 p.m. until midnight were developed and supervised by "Dream Team II", composed of four additional undergraduate students, three males and one female, who were selected from the three underrepresented minority societies, the American Indian Science and Engineering Society (AISES), the National Society of Black Engineers (NSBE) and the Society of Hispanic Professional Engineers (SHPE).

\section{Curriculum}

The program was developed by both teams, with the support of the Director and the Program Coordinator of the CEAS Minority Engineering Program and Dr. McNeill. The coach professor met with the students on several occasions to plan the program, made himself available as a consulting coach during the first week of the program, then allowed the students full autonomy over the instruction during the second week. His consulting fees were equal to one week's full salary. Dream Team I worked full time for one month prior to the beginning of the program.

Early in the discussions, it was decided that the curriculum must include certain skills that the students would need to excel in the ECE 100 course. These skills included: communications, computing, team work, and time management. In addition, the team wanted to include a certain 
amount of introduction to the university environment and to encourage the students to do research in the areas of financial aid, student health services, registrar services, and student organizations in engineering. In particular, they wanted the students to research the three minority engineering societies, AISES, NSBE, and SHPE.

The students of Dream Team I set to the task of preparing their curriculum. They did this through constant meetings and interaction with Dr. McNeill. The dream team had to develop a design project to be challenging enough to keep the participants very busy during their two week stay, yet be specific enough in the scope to be realistically finished in a two week program. The project could have multiple dimensions since it would be a team project and at the request of the program coordinator would need to be comprehensive enough to make the participants feel as though they would need very good time management and team building skills to complete it. It was the program coordinator's goal to make the participants simulate the time demands and pressures they would inevitably feel during their first semester.

The dream team also faced a challenge in that each student brought a certain expertise to the program curriculum, but they did not all have the same level of skills in each area. During the preparation time, the dream team members spent a considerable amount of time cross training each other in the programming languages, UNIX operating system, and team building curriculum. This cross training was not complete prior to the beginning of the program, but was sufficient enough that while one member was instructing the participants in an area, the other dream team members could answer individual questions and assist in the classroom. As a result of this cross training, the dream team members were expanding their skill set as well as instructing the participants. More details about the program content will be described in another paper.

Dream Team I and the MEP wanted the participants to interact with as many of their peers as possible and to have new experiences. Therefore, it was decided to determine the teams in advance instead of allowing the participants to pick their team members and possibly work with other participants that they knew or went to school with. This was also done so that the teams would be balanced according to computer knowledge and experience. The hope was that by balancing the team's computer skills, no team would have an advantage over the other. To do this, Dream Team I needed a method of ascertaining the participant's computer knowledge and past experience prior to the beginning of the program. They also decided that knowing this would help them in developing their presentations and lectures about computer skills. To determine this information, the dream team developed a computer questionnaire with yes or no responses that they sent to every participant. The information was gathered and analyzed and the teams were developed by taking into account the participant's computer knowledge, where they came from, their gender and ethnicity.

\section{Instruction}

The program began on a Monday evening with participant check-in at the dormitories. Both Dream Teams, Dr. McNeill, and the MEP staff were present to greet the participants and their parents. The opening meeting allowed time for the parents to meet the dream teams and the staff as well as ask questions about the program policies and procedures. Once the meeting finished, the participants had dinner and began getting to know their peers. Instruction began the next 
morning with program goals and expectations and continued on a daily basis, including Saturday, for the next nine days. Sunday the students were given free time in observation of religious activities. However, computer labs were reserved for the day and participants were strongly encouraged to spend the rest of the day working on project activities.

The dream team members were in contact with Dr. McNeill daily through e-mail transmissions throughout the planning and during the first week of the program. This practice was transferred to the participants in two ways. The participants were required to submit daily assignments through e-mail. They were also required to submit progress reports about their projects and ask clarification questions about the project requirements through e-mail. Secondly, at the request of Dream Team I, the MEP director and coordinator communicated with the participants through email to answer general questions about the university system.

Throughout the delivery of the program, the team had interaction with Dr. McNeill for advice on delivery and reorganization of concepts or content as needed. The team also convened after each module to discuss progress and to make modifications for the following sessions. At their own initiative, each day, the two dream teams met during dinner in a transition meeting to evaluate student progress in the program and to better plan for the evening's activities. Dream Team I would tell Dream Team II about the curriculum accomplishments during the day so that Dream Team II would know what to expect and what questions they would be asked when they took the students to the computer lab in the evening.

Throughout the course of the design project, Dream Team I had meetings with the teams. The purpose of these meetings were to engage the participants in an open discussion about their group progress as well as assess the success the participants were having in applying their team building skills and working together. The team building sessions were reserved for one on one interviews and discussions between each student team and the dream team. The participants in each team were asked to report on the team's progress and discuss any challenges they faced in working as a team. Dream Team I also set aside the morning sessions of second week for project critiques and progress evaluation. The goal was to have constant interaction with the teams and ensure that all the teams were progressing at the same rate toward the culmination of the project presentations.

Throughout the planning of the program both dream teams were required to maintain control books. These control books were housed in the MEP offices and contained all the information about all aspects of the program developed and delivered by the students. The curriculum control book contained sections developed individually by each dream team member and included handouts given to the participants as well as class plans and lectures. In addition, the control book contained overhead slides and presentation materials as they were developed.

Dream Team II developed the housing assignments with one criteria, participants that were on the same teams were not housed in the same rooms. Again the goal was to create community and to expose the participants to as many of their peers as possible. The control book for Dream Team II contained information regarding the students activities outside the classroom. The control book also contained information about the participants housing status and medical emergency forms. 


\section{Discussion}

The three members of Dream Team I learned many lessons throughout the course of the program. First and foremost, they learned that they had to present a united front to the participants during all elements of delivering the curriculum. This was especially important since the participants would be receiving no grade for their participation and would not be motivated by GPA to complete assignments and put forth effort. Their challenge was to excite these students about the topics and to encourage them to learn about the subject areas. They conveyed to the participants how importance of these topics and that they would benefit from what they were learning in their ECE 100 course, as well as throughout their academic career. In addition, all of the participants were guaranteed a $\$ 500.00$ scholarship for their participation and a portion of over $\$ 20,000$ in additional scholarships for the design competition. It was decided by the MEP, Dream Team I, and Dr. McNeill that the amounts of the additional scholarships would not be announced until the end of the program, only that the additional scholarships would be based on the final project and the team presentation. This was done to encourage the teams to work together because they wanted to learn together and not because they were hoping to win a certain amount of scholarship money.

During the second week, one particular group was struggling because one team member was not participating and doing an equal share of the work for the group project. During the team meetings with Dream Team I, it was becoming more and more evident that not only was the team member not participating, but the rest of the team members were shutting the member out. Dream Team I came to the MEP and asked for assistance and intervention with this particular group. Fortunately, the intervention from the MEP assisted the team, however, unfortunately, the intervention was too late in the program for the team to recover the time they had lost and their project had suffered from the team building problems they were having. The other lesson learned from this group was by the dream team themselves. They stated that they were learning to work together as a team as well and had they learned some of their lessons earlier, they would have asked for intervention sooner and possibly saved this particular team some time and frustration.

\section{Conclusion}

The participants related very well to instructor "peers". The instructors had credibility since they had been through the same type of curriculum. Student evaluations of the program were extremely positive with particularly high points for the instruction portion of the Web Page development. Dr. McNeill became very visible to the participants during the program and thus was not intimidating to the participants once they were enrolled in his ECE 100 course. Dr. McNeill also communicated that this freshman class of students in ECE 100 was one of the best classes he has worked with.

Although the student instructors taught teaming, at the same time, they were forced to learn a lot about teaming and teaching. They had several conflicts to resolve among themselves. The one element that they felt assisted them through their conflicts and challenges was their strong desire to teach the participants something helpful. This was very important to them because they were teaching what they wished they had learned prior to starting their degree. They felt that this 
desire and their true caring about each student made the experience exciting and worthwhile. One of the dream team members is now considering teaching as a career.

\section{References}

1. "Cohort Survival Analysis," University Office of Institutional Analysis, Arizona State University, Tempe, Arizona, Annual Report.

2. Arizona State University, General Catalog 1996-97, 1997-98, pg. 278.

3. Anderson-Rowland, Mary R., McCartney, Mary Ann, and Reyes, Maria A., "Successful Strategies for Minority Engineering Students” 1995 ASEE Annual Conference Proceedings, pg. 1944-1947.

\section{MARIA A. REYES}

Maria A. Reyes is a graduate of the Minority Engineering Program (MEP) at ASU, where she obtained a BS in Civil Engineering and is pursuing a Masters degree in Geotechnical Engineering. She spent two years as a staff engineer at a local consulting firm. Currently, she serves as the MEP Coordinator at ASU which has given her the opportunity to develop and teach a seminar course for entering minority students.

\section{MARY ANN MCCARTNEY}

Mary Ann McCartney serves as the Director of the Office of Minority Engineering Programs in the CEAS at ASU. Prior to joining ASU, she spent 18 years at IBM serving her last five years as Program Manager Academic and Community Relations. For two years she served as corporate liaison between IBM and the headquarters of the Mathematics, Engineering, Science Achievement Program at UC Berkeley.

\section{MARY R. ANDERSON-ROWLAND}

Mary R. Anderson-Rowland is the Associate Dean of Student Affairs and Special Programs for the College of Engineering and Applied Sciences at ASU. Her responsibilities include the Women In Applied Science and Engineering Program, the Office Of Minority Engineering Programs, and Recruitment, and Student Organizations. With a Ph.D. in Applied Statistics from the University of Iowa, she does research in the Area of Quality Control. 